\title{
A NEW SPECIES CLOSELY RESEMBLING DROSOPHILA MELANOGASTER.
}

\author{
By A. H. Sturtevant, \\ Columbia University, New York City.
}

In the course of genetic experiments with Drosophila melanogaster Meigen a wild race was found that gave unexpected results. Examination showed that it was structurally different from typical D. melanogaster. The new form has been found to be common and widely distributed. Since it is evidently a distinct species that has hitherto been overlooked, and since it will certainly be extensively discussed in genetic literature in the future, the following name and description are presented.

Drosophila simulans, sp. nov.

Closely similar to D. melanogaster Meigen in size, color, shape, venation, chaetotaxy, and in the presence of tarsal combs in the male. The eyes are a little larger and the cheeks a little narrower than in that species; but these differences are not sufficiently wellmarked to serve as diagnostic characters. The external male genitalia, shown in figure 2, are clearly distinct from those of $D$. melanogaster (figure 1): The most reliable differences here are in the size and shape of the posterior process ( $p$ ) of the large anterior plate, and in the shape and vestiture of the smaller comb-bearing plate (c). In relaxed pinned material the two species may be separated by means of the posterior process. In D. melanogaster it appears as a small hook; in D. simulans it resembles a clamshell, since the basal part is not usually observable.

Living material shows several other slight differences, not definite enough to serve for purposes of classification, but observable in large series as average differences. D. simulans has a slightly darker mesonotum, often with a bubble beneath the surface in the mid-dorsal line. The abdomen is a little stouter, the wings a little shorter. The dark abdominal bands of the female are not quite as deep black as those of $D$. melanogaster. The egg has two filaments at its anterior end, that are somewhat longer, and less dilated at their tips, than those of D. melanogaster.

Type, allotype, and gonotypes: bred, in New York City, from 
stock collected at Lakeland, Fla. (C. W. Metz). Type deposited at the American Museum of Natural History, New York City. The gonotypes are not descended from the type, but the whole type series is known to be descended from a single female.

Other specimens examined: Randolph, N. H. (Miss H. Daniels); Cold Spring Harbor (C. W. Metz), Staten Island (F. Schrader), N. Y.; Rochester, Minn. (L. Huckfield); Richmond, Va.; Macon, Ga. (G. I. Carver); Palm Beach, Fla. (B. B. Horton); Kushla, Ala.; Fayetteville, Ark. (B. Schwartz); Port Limon, Costa Rica.

Examination of genitalia shows that $D$. melanogaster has at least the following range: Nova Scotia to Oregon, California, and Florida; Cuba, Porto Rico, Costa Rica, Panama; Holland; Australia.

D. simulans and D. melanogaster may be crossed, though only with difficulty. The hybrids so far obtained have apparently all been sterile. They are obtained most easily from the mating of $D$. melanogaster female by $D$. simulans male; and from this cross only females are ordinarily produced. It was the discovery of this fact
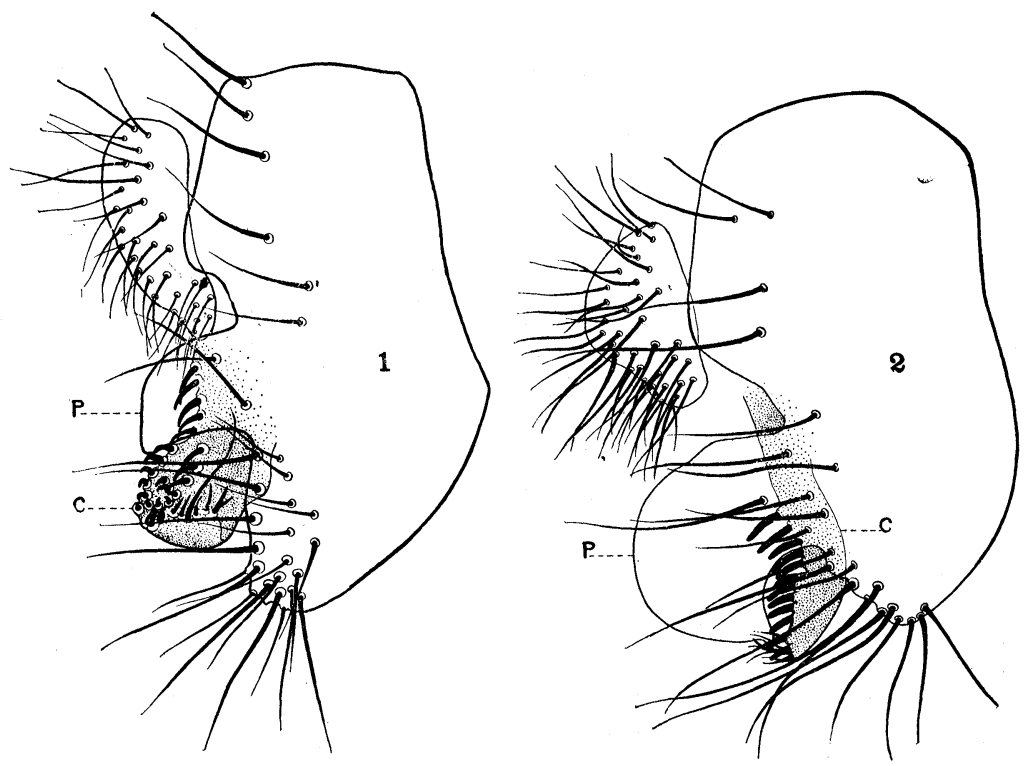

Fig. 1. 1, External male genitalia of Drosophila melanogaster Meig., from cleared material collected in Minnesota; 2, external male genitalia of Drosophila simulans sp. nov., from cleared material mounted in balsam. Gonotype. 
by Mr. A. M. Brown that led to the identification of $D$. simulans as a distinct species. Males have, however, been obtained by using D. melanogaster females that give what are known to students of heredity as "non-disjunctional exceptions." A full account of these experiments and a description of the hybrids will be published later. ${ }^{1}$

\section{DESCRIPTIONS OF NEW TRYPHONINA OF THE TRIBE CTENOPELMINI (HYMENOPTERA; ICHNEUMONID $A){ }^{2}$}

By Miss Esther W. Hall, Bussey Institution, Harvard University.

Polyblastus fulvilinealis sp. nov.

$0^{7}$. Length $6 \mathrm{~mm}$. Head wider than thorax, thickened behind eyes. Malar line equal to one-half the base of clypeus. Distance from ocellus to clypeus slightly longer than from eye to eye. Front protruding below antennæ, which are almost as long as body and composed of 28 segments. First flagellar joint slightly longer than scape and pedicel, four times as long as wide at apex. Fourteenth segment about twice as long as wide and one-half the length of first flagellar joint. Scutellum flat, margined. Pronotum prominent. Parapsidals present anteriorly. Areolation complete. Abdomen subsessile. Length of petiole two and one-half times width of base; width at apex twice that of base. Third segment twice as broad as long and one-fifth narrower than thorax. Carinæ with groove between and extending almost to apex. Base of hind coxæ to apex of femora longer than abdomen. Five teeth on claws. Wings large, areolet small, petiolate, rhomboidal. Head, except cheeks, finely punctate; thorax, except slightly rugulose propodeum, sparsely punctate; abdomen smooth.

Black. Rufous as follows: apical half of clypeus, collar, and lower pleuræ, propodeum, hind coxæ and femora, outside of four anterior femora. Antennæ and hind tarsi dusky. Mandibles except teeth, underside of pedicel, remainder of fore legs, hind

\footnotetext{
1 It seems highly probable that the sterile "unisexual broods" of Drosophila reported by Quackenbush (1910. Science, n. s. $32 ; 183-185)$ were hybrids between $D$. melanogaster and D. simulans.

2 Contributions from the Entomological Laboratory of the Bussy Institution, Harvard University, No. 167.
} 

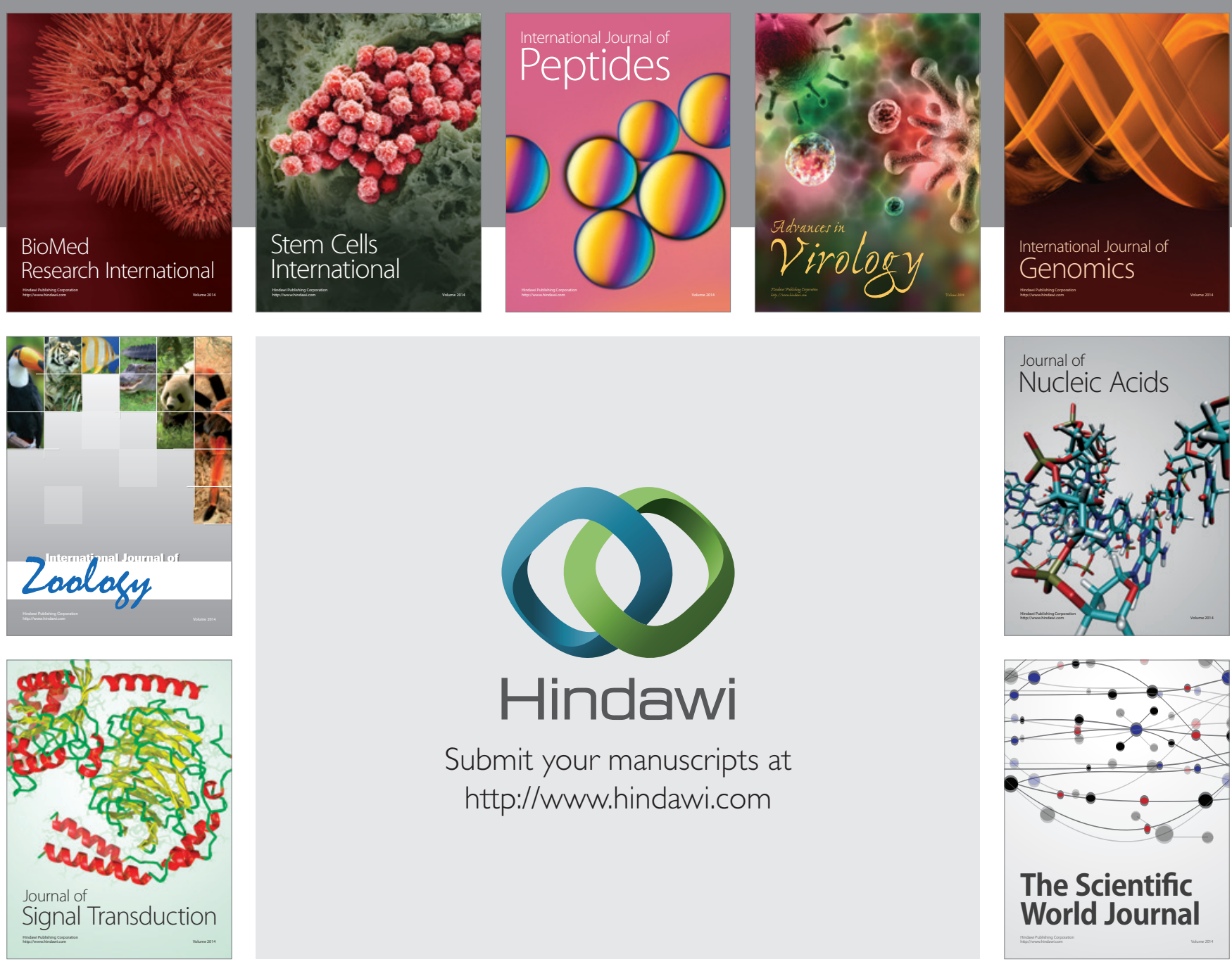

Submit your manuscripts at

http://www.hindawi.com
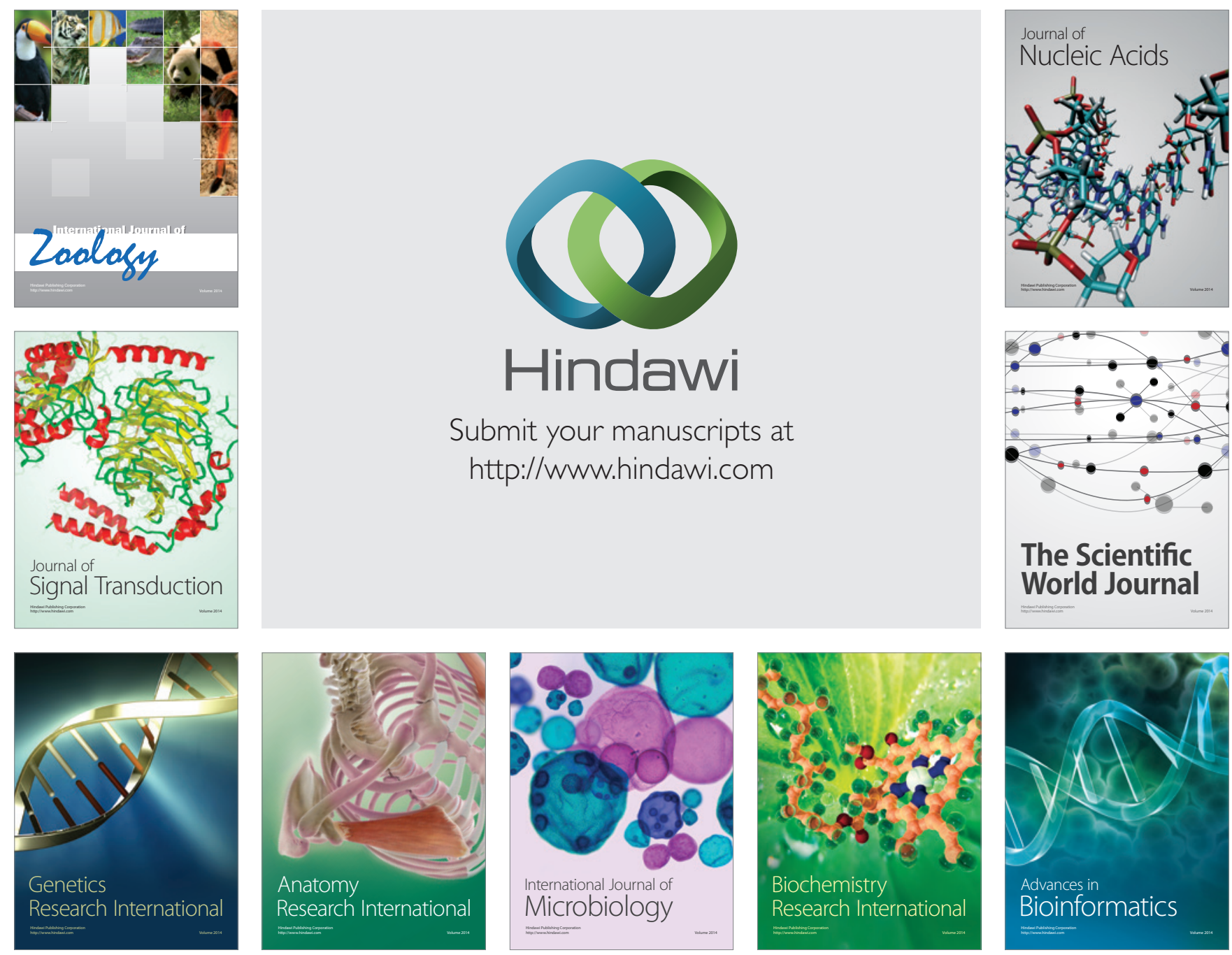

The Scientific World Journal
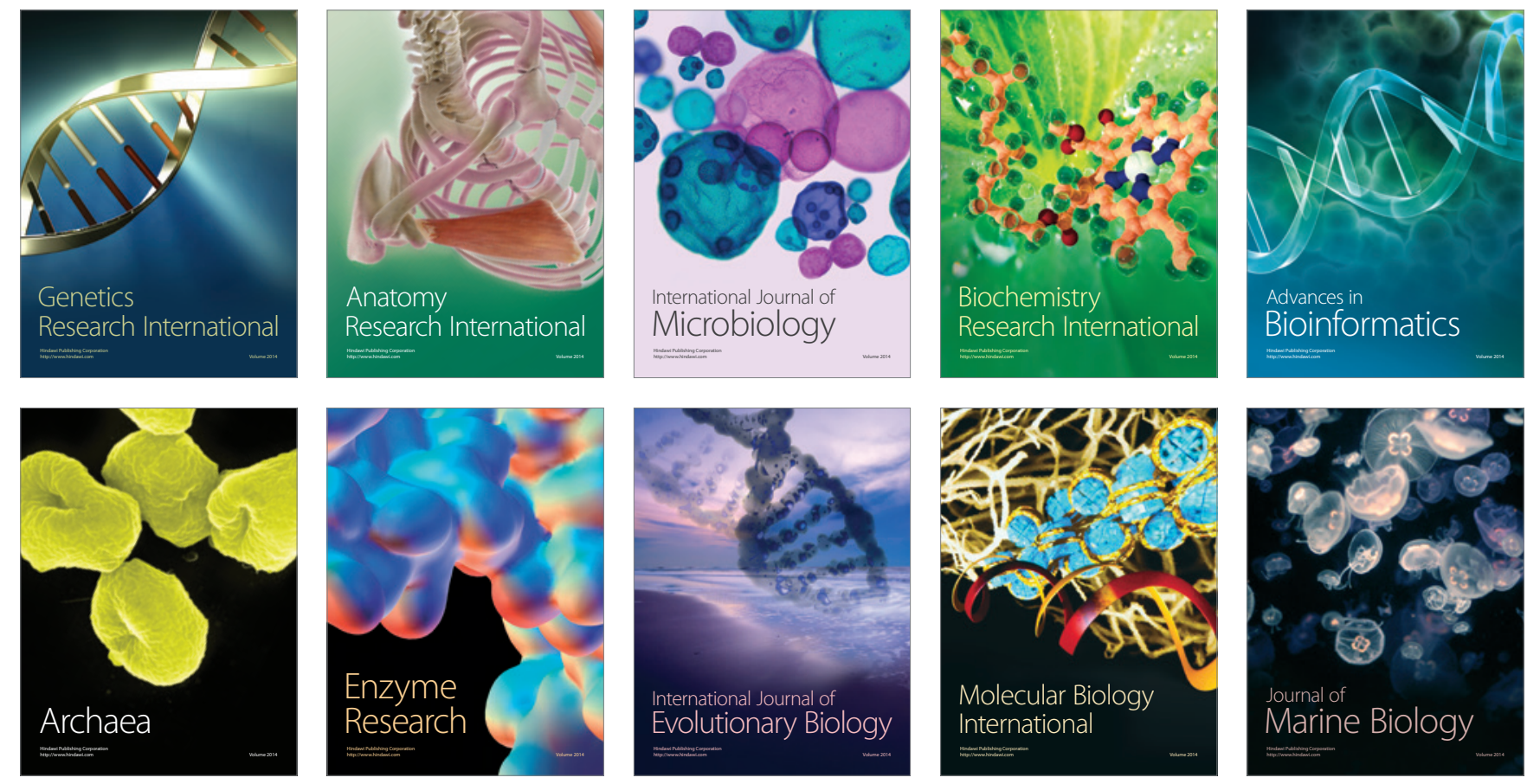